\title{
PRESENCIA AUSENTE O AUSENCIA PRESENTE DE DIOS EN LA MUERTE LENTA DE JUSTO SOTELO
}

\section{GOD'S ABSENT PRESENCE OR PRESENT ABSENCE IN JUSTO SOTELO'S LA MUERTE LENTA}

\author{
Patrick Toumba Haman \\ Universidad de Maroua. Camerún
}

\section{ABSTRACT}

In Postmodern literary, in general, most of the texts are full of characters in crisis of values and in discordance with the spaces where they are placed. For instance, to look forward a solution, either they become introverted or they look for an external reality, unless the latest is not always clearly seizable. The present work is centred on Justo Sotelo's La muerte lenta (1995) and questions the declarations and actions of the protagonist, especially through the high presence of number three, symbol of Trinity, as well as the narration in second person, both understandable as marks of the God's presence. The objective is, therefore, to question the opportunity of such a liquid presence so that to seize the mobiles of the protagonist and read then the deep meaning of the novel and the social commitment of the author. The semiotic approach will help us to reach such results.

Key words: Literary postmodernity, crisis, fictional texts, God, liquid presence. 


\section{RESUMEN}

En la postmodernidad literaria, en general, abundan textos con personajes en crisis de valores y en disonancia con los espacios en los que se mueven. Por lo tanto, a modo de solución, estos van refugiándose ellos mismos o buscan una realidad externa a la que aferrarse, aunque no siempre se percibe esta de manera clara. La presente reflexión se centra en La muerte lenta (1995) de Justo Sotelo e interroga las declaraciones y actuaciones del protagonista, de las que sobresale la fuerte presencia del número tres, símbolo de la Trinidad, así como la narración en la segunda persona, hechos que luego se entienden como las huellas de la presencia de Dios. La finalidad es, entonces, cuestionar la oportunidad de tal presencia líquida para interpretar esos móviles del protagonista y captar así la significación profunda de la obra y el compromiso social del autor. El método semiótico será el idóneo para llegar a tales resultados.

Palabras clave: Postmodernidad literaria, crisis, textos novelescos, Dios, presencia líquida.

Fecha de recepción 6 de abril de 2020.

Fecha de aceptación: 26 de mayo de 2020.

Cómo citar: Toumba Haman, Patrick (2020), «Presencia ausente o ausencia presente de Dios en La muerte lenta de Justo Sotelo», en Actio Nova: Revista de Teoría de la Literatura y Literatura Comparada, 4: 66-83.

DOI: https://doi.org/10.15366/actionova2020.4.004 
Dios, en la literatura en general, suele manifestarse a través de varias figuras y reviste de muchos atributos. Puede evocar un deseo, una espera, una esperanza o simplemente orientar la conducta de un personaje o constituirse en el árbitro, si se atiende a su carácter omnisciente. Dios es manifestación y silencio a la vez. A veces no se le nombra de manera directa. En la literatura española contemporánea, reflejo de la época posmoderna en la que encaja el texto que nos proponemos analizar, sigue presente la imagen de Dios aunque podría decirse que su presencia es menos ostensible que en siglos pasados ${ }^{1}$. En palabras de Juan Rubio Fernández (2013), en una comunicación sobre las huellas de Dios en la literatura contemporánea, «evidentemente no está [Dios] presente como en las obras del Padre Coloma. [...] Dios está presente en la novela contemporánea, pero está con su silencio». Ello se debe entonces a que la postmodernidad es la crítica de la modernidad que es, a su vez, y entre otras cosas, la del cristianismo tradicional. La presente reflexión se centra en la primera novela de Justo Sotelo, La muerte lenta (1995), con la finalidad de entender cómo se puede leer este ente supremo en el recorrido, los deseos y esperas del narrador intradiegético. En este sentido, demostraremos cómo se manifiesta Dios, partiendo de la función titulógica, en relación con el corpus y, sobre todo, a través de la presencia constante del número tres, cifra harto significativa a la hora de captar el sentido de Dios en la doctrina cristiana, ya que «où que l'on aille, que ce soit tout près de nous ou au bout du monde, il est inévitable qu'on retrouvera la trace de Dieu à travers les nombres» (Desrosiers, 2005: 15). Pero es de notar que no se tratará de llevar a cabo un estudio sistemático sobre Dios, por el carácter difícilmente asequible de los textos postmodernos, por lo que solo nos detendremos en lo que nos parezcan las huellas de la lectura de la presencia de este Ente Supremo.

El narrador de La muerte lenta (1995) cuenta, en primera y segunda personas, la historia de su infancia y, sobre todo, de su juventud con los recuerdos del colegio, sus contactos con el mundo profesional, sus relaciones amorosas interesadas y sus sueños de formar parte de los ejecutivos de la entidad bancaria donde trabaja. La novela también es, sobre todo, un homenaje del narrador a su amigo Enrique Espejo, toxicómano que representa, como indica su apellido, una superficie desde la que se mira el narrador para darse cuenta de su existencia presente. Enrique se convierte desde luego en una panacea, en un puente por el que accede el narrador a su vida pasada. Incluso el narrador está preocupado

\footnotetext{
${ }^{1}$ Eagleton (2014) parece pensar lo contrario, ya que, en su opinión, Dios sobrevive al racionalismo del XVIII, al romanticismo y reaparece en nuestra época sin fe.
} 
por su salvación ya que cree en Dios («yo tenía un año y aún no creía en Dios» (Sotelo, 1995: 15)), y su salvación parece estar supeditada a los recuerdos que tiene de su amigo, nacido un 25 de diciembre, cuando apunta: «Tú serías para mí el mismísimo Jesucristo» (Sotelo, 1995: 15). Son constantes los diálogos entre ambos personajes, a modo de soliloquio: «Te fuiste, pero no pude olvidarte, jamás podré» (Sotelo, 1995: 35). Además del vínculo entre ambos personajes, la novela también es una muestra artística plagada de alusiones a cantantes, músicos, escritores, etc.

Este trabajo está basado en la semiótica, «ciencia de los discursos» (Kristeva, 1978: 22), como método de análisis e interpretación del texto, que es la novela que nos interesa aquí. En este sentido, el texto literario, por la complejidad del material lingüístico que lo constituye, es capaz de producir sentidos sorprendentes incluso para su propio autor. Además, su interpretación puede tomar en cuenta el espacio y la época en que ha vivido o vive el lector, su cultura y religión, sus gustos y preferencias, entre otras cosas según opina Milagros Ezquerro (1998: 92). El método semiótico es el apropiado aquí por su transdisciplinariedad, pero también y sobre todo porque la comunicación se basa en el signo como construcción real de la inteligencia, y específicamente en el símbolo convencional, la cifra tres, que puede entonces tratarse desde varias miradas científicas. También porque la reflexión se centra en el lenguaje, complejo por su esencia como ya queda señalado. También y sobre todo porque el signo que analizamos se inscribe dentro de la postmodernidad que, en palabras de Vattimo (2004), marca el «ocaso de Occidente» donde ya no existe la Verdad sino verdades o donde a falta de grandes relatos, nos encontramos, en términos del narrador de La muerte lenta, con «la falta de grandes pensadores en la actualidad» (Sotelo, 1995: 66). En este sentido, los resultados a los que llegaremos solo serían una verdad y una mirada entre tantas otras. Ya que, como afirma Todorov (1993: 256), «la obra de arte no es más que conexiones».

Esta reflexión no es del todo puramente religiosa ni tiene la intención de serlo ya que nos apoyamos en el mencionado corpus literario, pero de vez en cuando aludiremos a algún hecho bíblico para mostrar las huellas de la presencia de Dios en el texto analizado. Se divide en tres apartados: primero, se tratará de la justificación del título de la reflexión y en segundo lugar, de la búsqueda de los indicios de la presencia de Dios a través de la cifra tres y la instancia narradora, como veremos. Por fin, intentaremos hacer una lectura social de la obra de cara a perfilar el proyecto de sociedad de Justo Sotelo. 


\section{I- LA MUERTE LENTA: JUSTIFICACIÓN Y FUNCIÓN DEL TÍTULO}

¿Por qué el título del presente artículo, «Presencia ausente o ausencia presente de Dios en La muerte lenta...»? La respuesta a esta interrogación constituirá el hilo conductor de este apartado. «Presencia ausente» porque existen signos textuales que dan cuenta de su presencia que en realidad no se ve sino a través de una operación de análisis e interpretación. Desde otro ángulo, «ausencia presente», ya que el vocablo que nos une aquí, «Dios», viene muy pocas veces en toda la novela, una decena de veces, exactamente doce veces (p.15 dos veces, p. 36, 46, 47, 50, dos veces; p.71, 105, 107, 132 y 141), cifra también muy significativa en relación al tema de Dios. A pesar de esta poca presencia, podemos hacer una lectura de su presencia en la obra. Primero, el narrador cree en Dios, como es observable entre el «yo tenía un año y aún no creía en Dios» (Sotelo, 1995: 15) y el «Salomé [novia de su amigo Enrique y nombre tan significativo] no pudo hablar más conmigo, a ella también había que enseñarle a creer en Dios» (Sotelo, 1995: 132). Del mismo modo, el lector se da cuenta del sometimiento del propio narrador casi siempre que él habla de Dios, a través de esta fórmula constante y repetitiva que aparece tres veces: «como Dios manda» (Sotelo, 1995: 15, 47, 71).

Tras recorrer esta misma novela, no aparece de manera nítida la presencia de Dios. Esta dificultad de aprehenderlo es también y sobre todo lo que motiva esta reflexión, ya que, como en palabras de otro narrador de Sotelo (2017: 128), «considero que es más importante lo que no se dice que lo que se dice». En cualquier caso, que sea la presencia ausente o la ausencia presente de Dios, que es esencialmente imagen, espíritu, luz y amor, cualquier lector preparado de La muerte lenta se percataría de modo rápido del carácter fluido y transparente de este ente supremo en esta novela, de Sotelo, que se inscribe en una dinámica universal. A lo mejor, para entender el carácter etéreo de Dios, conviene recurrir a la opinión del crítico postmoderno Zygmunt Bauman (2003) para quien Dios está relegado al pasado, y que se ha hecho líquido en la posmodernidad. La propia presencia indirecta de Dios en el título de la novela, La muerte lenta, tiene entonces que ver en parte con el que donde no haya muerte, poco se hablaría de Dios, porque en varios casos Dios suele entrar en las vidas de los seres humanos cuando se ponen a pensar en el final, el más allá. De hecho, afirma Ernesto Sábato (2014: 88) que «la literatura de hoy no se propone la belleza como fin (...). Más bien es un intento de ahondar en el sentido general de la existencia, una dolorosa tentativa de llegar hasta el fondo del misterio». Este sentido general de la existencia como realidad propia a 
todos los seres humanos nos interpela sobre la muerte y, por consiguiente, sobre Dios, de ahí la oportunidad de esta temática universal. Ya que, como apunta Eagleton (2017: 206), «en realidad, un problema relacionado con el tratamiento de cuestiones universales y no locales por parte de todas las grandes obras de la literatura es que pocas emociones humanas están confinadas a culturas específicas».

A primera vista, el título de la novela que analizamos, La muerte lenta ${ }^{2}$, puede hacer referencia a la muerte de Cristo, por la pasión, lenta por los sufrimientos del Hijo del Hombre, si se supone que según las creencias del cristianismo ha muerto antes de resucitar. Además, en este artículo asimilamos a Jesús con Dios, enfocándonos en sus dichos y actos ya que según parece, él fue más que un simple hombre. Sólo por limitarnos en unos pocos detalles, la Sagrada Biblia (2012) deja transparentar que Jesús afirmó ser Dios o ser igual a Dios (Colosenses 2, 9). Él declaró tener el poder de Dios. Tuvo el poder de perdonar pecados (Marcos 2, 5-7) o de levantar a las personas de entre los muertos (Juan 5, 25-29). Operó muchos milagros invirtiendo así las leyes de la naturaleza. Vivió una vida sin pecado... Para reforzar esta idea de asimilación de ambas entidades, nos apoyamos en Julia Kristeva (1986: 62) según quien:

este Dios, como para acercarse más al lugar del hombre que lo invoca, es un «señor Jesucristo, el Hijo único de Dios». Engendrado por Dios, comparte su esencia, le es «consustancial», lo que queda especificado por la distinción «engendrado y no creado», ya que la criatura, en tanto creada, no podría ser idéntica al Creador.

La cifra tres está presente en toda la vida de Jesús. Y existen también muchas relaciones entre la propia muerte, lenta, de Jesús y el número tres, cifra en la que nos detendremos luego: se colocó a Jesús en la cruz en la tercera hora del día, murió a la hora novena, la oscuridad cubrió la tierra durante tres horas, resucitó al tercer día o tres mujeres, María, María Magdalena y Salomé, acudieron a su sepultura. En este caso, La muerte lenta,

\footnotetext{
${ }^{2}$ Es indiscutible que el título de la obra artística, en general y de la novela, en particular, ha sido el objeto de varias reflexiones por parte de la crítica. Es un elemento periférico pero que no debe sobrevolar cualquier lector ya que, en la mayoría de los casos, el título mantiene un vínculo con el texto. En cuanto elemento del paratexto, es capaz de influir negativa o positivamente en la recepción de la obra. El texto es una mercancía y el título, un anuncio, un código metalingüístico consistente en disponer al lector en condiciones necesarias para el apetito. Por lo que el título cumple una función aperitiva, según Barthes (1993: 329). Según Miguel Ángel de la Fuente González (1997-1998: 186-200), el título es fundamental antes de la lectura, durante, así como después de la misma, por lo que cumple varias funciones: denominativo-diferenciadora, referencial, expresiva, jerarquizadora, orientadora y posterior. Jean-Claude Mbarga (1991: 341-342) habla de la función incitativa, conativa o anticipadora del título por cuanto programa el comportamiento de lectura, así como de su función ideológica porque «posibilita a veces una lectura ideológica del texto, ya que remite a un código moral y/o social».
} 
título de la obra por el que se puede leer a Jesús, es un trampolín que nos conduce a Dios ${ }^{3}$ ya que como el misterio de la trinidad, está constituido este título (La muerte lenta) de tres palabras.

La presencia de Dios también tiene que ver con nuestras identidades y a lo largo de la obra, el protagonista va construyéndose teniendo en cuenta el que sus identidades están dispersas en el pasado y el presente, están fragmentadas y sus partes quedan en Van Gogh, su juventud y su amigo Enrique Espejo. La reconstitución de estos tres elementos significaría la recuperación de la identidad pasada del protagonista útil para el momento presente. De la misma forma, a modo de paralelismo, aparece Jesús, como se ha visto en el título de la novela de Sotelo, como parte fragmentada y constituyente de la Trinidad de la que está formado Dios y, en definitiva, como la propia metáfora del Dios evanescente y transparente que es entonces un espejo en el que se mira el protagonista. Interesémonos ahora por el sentido del número tres en la obra que analizamos.

\section{II- EL SIGNIFICADO DEL NÚMERO TRES EN LA MUERTE LENTA}

Fundamentalmente, el número tres es lo que da más sentido a nuestra reflexión en el marco de este artículo. Es, en gran medida, lo que nos lleva a deducir la presencia de Dios en la novela que analizamos. De modo general, se ha estudiado el número tres en muchos ámbitos de las disciplinas científicas. Es sin duda uno de los números con mayor significación y determinación en nuestras vidas y creencias. Para Platón, el número tres simboliza la imagen del Ser Supremo en sus tres personalidades (Material, Espiritual e Intelectual) y en Aristóteles determina la Unidad del Hombre y contiene en sí al Principio, al Medio y al Fin. De los estudios llevados a cabo sobre la Biblia, el número tres aparece unas centenas de veces, «523 veces» según Desrosiers (2005: 27). Es el número más sagrado y el primero de

\footnotetext{
${ }^{3}$ En las novelas posteriores de Sotelo, aparece más claramente la presencia de Dios, también a través del número tres. En Las mentiras inexactas, por ejemplo, se lee en una escena erótica protagonizada por tres personajes, incluido el narrador: «Éramos siempre tres: tú, yo y el otro. ¡El otro que siempre nos separaba! Un ser invisible y ciego, sordo y mudo. ¿Recuerdas hombre? Los tres juntos, haciendo el amor los tres, amándoos tú y él, y yo contigo, y él conmigo» (2012: 161). Incluso los personajes reconocen la existencia de Dios, aunque la simulan en ocasiones con 'dios', como aparece en las palabras de Albertina, la última poeta del veintisiete, dirigidas a Sergio, el joven librero: «Creo en ti...Creo en tu padre...Creo en el hijo que nunca tendremos... Mis palabras sólo recordaron lo que fueron cuando tú, Sergio, las enseñaste a sentir, porque sabemos que dios existe» (2012: 163). Son también mucho más presentes alusiones a Dios en Entrevías mon amour (2009), del mismo autor, y empiezan por el propio narrador, el reportero Teo Abad, educado según los preceptos del cristianismo.
} 
los cuatro números espiritualmente perfectos (los tres otros son el 7, el 10 y el 12). El número tres es entonces lo que nos lleva a acercar esta reflexión a la imagen de Dios, a la presencia ausente o ausencia presente de Dios en la novela analizada. Porque el propio Dios es Trinidad (Padre, Hijo y Espíritu Santo), Dios como ser 'tres', trascendente es el que es, el que era y el que ha de ser.

Una de las mayores preocupaciones del narrador de La muerte lenta es su salvación. Esta pasa por el pasado o la memoria, realidad que busca constantemente a lo largo de las páginas que constituyen la novela. Pero esta salvación ${ }^{5}$ se lee a través del número tres si por analogía se supone que Jesús murió a los treinta y tres años para resucitar al tercer día de su muerte. Aparece el número tres desde el íncipit, cuando apunta el narrador que tiene poco más de treinta años, edad que se asimilaría con la de Jesús a su muerte: «Hay tres cadáveres en mi vida: mi juventud, Van Gogh y Enrique Espejo» (Sotelo, 1995: 13). Si en realidad lo que denomina «cadáveres» lo son por situarse ya en su pasado, es importante mencionar que siguen obsesionando al narrador hasta el punto de condicionar sus acciones y vivencias. Está preso de su pasado, de lo que simboliza su personalidad artística y su apego a su confidente Enrique. Conforme nos adentramos en la novela, hay una sensación de que el número tres ocupa un sitio de interés en la estructura de las diferentes historias de la novela que nos va presentando el narrador, como son el círculo familiar de su amigo Enrique, así como el entorno del banco donde trabaja, entre otras. Por ejemplo y en relación al número tres, dirigiéndose indirectamente a su amigo, dice: «Ya estaba en tu casa tu hermano Antonio, tres años mayor que tú; después vendría, en cabal consonancia, tu hermano Ángel, tres años menor que tú» (Sotelo, 1995: 16-17). Además, como menciona el narrador, el padre de Enrique «nació ansiosamente a la vida con más de treinta años» (Sotelo, 1995: 17). Esta fuerte relación con Enrique se nota en la obra. Dice el narrador, por ejemplo, al dirigirse a su amigo:

El asunto terminó incluso en una imprenta: tú eras el teórico, tu tío hacía de rotulista y letrista, no precisamente un Ibarra, y yo de cronista sin madonna. Llegamos a encuadernar doce volúmenes sobre tu testamento ideológico. Conseguimos vender tres tomitos vermiformes que nos colmaron de gozo y satisfacción; el milagro se había realizado. [...] Resultaba pintoresco contemplarnos a los tres en la esquina de la calle Arenal, mientras tú tocabas la

\footnotetext{
${ }^{4}$ Para tener más informaciones acerca del simbolismo del número tres, véase a Steve Desrosiers (2005: 22-27). También es de interés el libro de Northrop Frye (1982) donde el autor se propone hacer una interpretación literaria de la Biblia, en contraposición a la teológica.

${ }^{5}$ José Díaz Murugarren (1989) destaca tres atributos o características fundamentales de Dios en las Sagradas Escrituras, a saber, Dios como creador del mundo, Dios como legislador y Dios como salvador del hombre. Nos apoyamos en este último atributo para fundamentar la idea de la salvación, ya que metafóricamente, parece que la salvación del protagonista pasa por el número tres que asociamos entonces a la figura de Dios.
} 
flauta, yo recitaba versos de San Juan de la Cruz y tu tío aplaudía intentando atraer la atención del escaso público (Sotelo, 1995: 31).

Existen más referencias textuales donde está presente la cifra tres en los diferentes relatos del narrador intradiegético, según se puede notar en las numerosas citas textuales siguientes: «como dicen que no existen dos sin tres, quiero referirme en ese momento, si me sigues escuchando, a la tercera idea que nos quiso transmitir el excesivo» (Sotelo, 1995: 32); «Los tres sentíamos pero yo sentía más, porque sentía la música dentro de mí y porque no la sabía explicar» (Sotelo, 1995: 37); «En dos o tres meses me había cambiado el aspecto físico» (Sotelo, 1995: 45); «Realmente en Rosa tampoco pude apreciar a una mujer -Tenía tres años más que yo-» (Sotelo, 1995: 49); «A través de la Universidad recibí dos o tres propuestas de empleo que me hicieron perder mi ya escasa inocencia» (Sotelo, 1995: 49); «ise sitúa el treinta por ciento la tarifa impositiva del impuesto de sociedades?» (Sotelo, 1995: 50); «Como apoderado, durante tres años, de la oficina bancaria me sentía enormemente feliz» (Sotelo, 1995: 54); «pero me convertí de la noche a la mañana en la segunda persona más relevante del equipo que coordinaba la tercera parte de oficinas -quince en concreto- del Banco en Madrid» (Sotelo, 1995: 61); «Algunos sábados quedaba con dos o tres compañeros de la facultad para tomar unas copas» (Sotelo, 1995: 63); «a pesar de su edad [Leonor], sólo había conocido, y de refilón, a tres hombres» (Sotelo, 1995: 74); «Una hora antes de que el destartalado tren de cercanías rompiera mis oídos, y los de tres o cuatro personas más, me encontraba...» (Sotelo, 1995: 75); «Y la última resaca se llenó de este tiempo inexistente, del tuyo, de las treinta monedas y del mío, sobre todo del mío» (Sotelo, 1995: 86); etc. Si la importancia de Enrique para el narrador está suficientemente demostrada, cabe recordar que Antonio también le facilita el contacto con el pasado, una vez que llega al lugar de la adolescencia, alquilándole espacios para recapacitarse. Y en última instancia, el nombre Ángel es harto significativo y corre pareja con la idea de la salvación a la que hemos aludido anteriormente.

Por lo que se refiere al banco donde trabaja, el narrador introduce la figura de tres mujeres empleadas, Susana, Irene y Marga, a las que presenta como mujeres que quieren convencerle a que abandone definitivamente a su propia esposa, Leonor, y se case con ellas (Sotelo, 1995: 88). También en el medio profesional, el narrador, para buscar una solución en relación a una oferta pública de adquisición de acciones, recurre a los servicios de una joven estudiante, Carmina, quien piensa poder solicitar el apoyo de otra compañera de clase y dice entonces: «quizás entre los tres...» (Sotelo, 1995: 116). De este trío, es decir, el 
narrador, Carmina y Rosa María, esta última, Rosa María, es tres años mayor que el narrador. Además, el mismo narrador, al aludir al momento en que se le propone a Arturo Rey introducirle en el instituto, precisa que la mujer de este está embarazada de tres meses (Sotelo, 1995: 73).

Según hemos señalado anteriormente, la novela está plagada de referencias textuales, de citas de autores y en una de ellas, que es de Adriano y Yourcenar, leemos: «Como todo el mundo solo tengo a mi servicio tres medios para evaluar la existencia humana: el estudio de mí mismo, la observación de los hombres y los libros» (Sotelo, 1995: 142). Para terminar, hacia el final del texto, cuando en el soliloquio, el narrador se dirige a Enrique diciéndole que Figueroa ha escrito tres artículos en los que le denuncia por su implicación en el tráfico de estupefacientes (Sotelo, 1995: 149). Como el íncipit, «Hay tres cadáveres en mi vida» (Sotelo, 1995: 13), también aparece el número tres en el éxcipit, cuando pregunta el narrador: «¿De qué me sirven ya las treinta monedas?» (Sotelo, 1995: 155), palabras que recuerdan la traición de Jesús por Judas, asimilable en la obra con el propio narrador protagonista. Ambas oraciones dejan transparentar un tono de desesperanza del narrador por un pasado que se le escapa y que, en definitiva, no ha conseguido conciliar. La cifra «tres» se interpretaría entonces como una esperanza del narrador, quien busca salvación, a pesar de su decrepitud y hundimiento al final de la novela.

Otro rasgo, quizá de menor importancia, por el que se pueden captar las huellas de Dios, se sitúa a nivel del lenguaje. Como sabemos, por la influencia de la nueva novela hispanoamericana muchos cambios se operaron en la novela española a partir de la década de los 50 del pasado siglo. Uno de estos cambios es observable a nivel del acto de narrar. Como bien subraya Gutiérrez Carbajo (2013: 262), «junto a la primera y a la tercera persona narrativa, se introduce también el uso de la segunda, ensayado magistralmente por Michel Butor y Carlos Fuentes entre otros ${ }^{6}{ }^{\prime}$. En La muerte lenta, el narrador, además de la primera persona, utiliza mucho la segunda persona para dirigirse a su amigo Enrique, a quien considera su Jesucristo. Con él, físicamente ausente, entabla un diálogo como uno entablaría un diálogo con Dios en una plegaria. A lo largo de las páginas que constituyen la novela, el narrador utiliza entonces el 'tú', aunque sabe que no va a recibir ninguna respuesta directa por parte de su interlocutor, que no existe sino en sus imborrables recuerdos. Conoce muy

\footnotetext{
${ }^{6}$ En relación con la narración en segunda persona, mucho antes que Gutiérrez Carbajo y los demás autores, se puede recurrir al estilo y a la bibliografía de Baquero Goyanes, en los que se apoya Michel Butor para redactar La modification (1957).
} 
bien a la familia de su amigo Enrique, lo que se justifica por la fuerte presencia de estas expresiones que usa: «tu padre...» (15, 17, tres veces; 18, dos veces; 19, dos veces...) o «tu madre...» (15, dos veces; 16 , dos veces; $17,18 \ldots)$, por limitarnos tan solo a algunas de las páginas donde aparecen con frecuencia. En estos diálogos, alternan el pasado y el presente para marcar la distancia con el pasado común vivido por ambos personajes, así como actualizar esos recuerdos que contribuyen al desvelo y a la construcción de la personalidad del narrador. Son significativas del lazo entre ambos personajes las siguientes palabras del mismo narrador: «Te fuiste, pero no pude olvidarte, jamás podré. Tenía veinte años, esa edad bisagra, cuando decidí escribir sobre ti. Busqué más tu reflejo en todo lo que te rodeaba, yo incluido, y no tanto tu propia personalidad» (Sotelo, 1995: 35).

El vínculo es tan fuerte entre ambos personajes- «Yo soy tú» (Sotelo, 1995: 24) que incluso a veces, a pesar del diálogo unidireccional, el protagonista parece solicitar el visto bueno de su amigo para abordar cierto tema o conversación: «Déjame referirme unos instantes a Antonio, para cerrar tu círculo familiar más próximo; confieso que Ángel nunca me ha preocupado con exceso» (Sotelo, 1995: 21). Utiliza los recursos «¿Verdad, Enrique?» (Sotelo, 1995: 19, 24), «Escucha, no me interrumpas» (Sotelo, 1995: 23), « ¿Recuerdas, Enrique?» (Sotelo, 1995: 25), «نंigues recordando?» (Sotelo, 1995: 30), «نme oyes?» (Sotelo, 1995: 32), «... si me sigues escuchando...» (Sotelo, 1995: 32), «Como ves» (Sotelo, 1995: 45), «Me explicaré» (Sotelo, 1995: 47), «¿Qué querías que hiciera yo, Enrique?» (Sotelo, 1995: 47), «Como podrás suponer» (Sotelo, 1995: 54), «ino crees, Enrique?» (Sotelo, 1995: 65), «Te confieso que...» (Sotelo, 1995: 66), «ंte lo había dicho antes, no es eso?» (Sotelo, 1995: 76), «¿no es así, Enrique?» (Sotelo, 1995: 77), entre otros, para convencerse de que le escucha su amigo. De hecho, parece que escribir sobre su desaparecido amigo le permite al protagonista saldar una deuda profunda de su infancia y su adolescencia comunes. Ante el vacío de la ausencia de Enrique, le acucia la idea de rescatar la memoria, ese periodo tan importante de su vida.

En suma, La muerte lenta está plagada de referencias textuales, por la boca del narrador intradiegético, en que aparece una fuerte presencia del número tres y sus variantes. Además, la obra, en forma de soliloquio, deja transparentar un diálogo, unidireccional, entablado por el propio narrador con su amigo de infancia y adolescencia, Enrique Espejo. A nuestro parecer y si ningún texto literario es neutro, merece la pena detenernos un poco para sacar una lectura de tales elementos repetitivos, de ahí el siguiente apartado. 


\section{III- UNA CLAVE INTERPRETATIVA DE LA MUERTE LENTA}

El texto literario es un sistema complejo si nos atenemos al material lingüístico que lo constituye. No siempre se leen a primera vista los mensajes que es capaz de producir y su lectura es el resultado de varias operaciones. En este sentido y de acuerdo con la no linealidad del mensaje de este tipo de texto, opina Kristeva (1978: 239) que «el texto literario se presenta como un sistema de conexiones múltiples que se podría definir como una estructura de redes paragramáticas». Abundando en la misma dirección, ya apuntaba Todorov (1974: 12):

La primera operación de la lectura es trastornar el orden aparente en el que se constituye el texto: acercar las partes alejadas, descubrir repeticiones, oposiciones, gradaciones. Trastomar no quiere decir ignorar: el orden de encadenamiento no es indiferente, no es una pura «forma» (nada lo es, en el texto), pero tiene significación tanto por lo que muestra como por lo que oculta.

¿Cómo captar el sentido profundo del número tres en la novela analizada? Tal interrogación es la que sustenta este último apartado. En efecto, no vamos a perder de vista el que la novela es, en parte, el reflejo de la personalidad de su autor. Incluso, a veces, como opina Ezquerro, el texto es capaz de producir más sentido de lo esperado por su creador. En los análisis previos, hemos llegado a la conclusión según la cual La muerte lenta está muy relacionada con la salvación de su protagonista, de ahí la fuerte presencia del número tres, símbolo de Dios, en el misterio de la trinidad, tema en sí complejo. Ya que en palabras de Pérez B. (2012: 132), «expresar el pensamiento que la posmodernidad posee sobre Dios, no es una cuestión del todo sencilla». Además, como ya se ha señalado, una de las relevantes características de los textos postmodernos- y de la propia postmodernidad- es su ambigüedad y sus contradicciones. Ello resulta del que el fin de la modernidad, acentuado por la crisis postestructuralista,

aboga por el relativismo e, incluso, por la destrucción del significado: nos enseña que no es posible fijar un significado único, estable y central en los textos, que la palabra escrita está inmersa en un proceso pragmático que anula la posibilidad de comprensión única y la inserta en un juego indefinido de semiosis, en la polisemia inestable e indefinida (Lozano Mijares, 2007: 81).

¿Qué lecturas pueden hacerse de Dios en La muerte lenta de Justo Sotelo? Nos valdremos esencialmente de la interpretación para tal resultado. Como señala Eco (1992: 29), interpretar supone fidelidad y libertad. Por lo tanto, mediante esta operación queremos buscar en el texto lo que quería decir el autor y a la vez lo que dice el propio texto, 
independientemente de las intenciones de su autor. A la luz de los hechos analizados anteriormente, llegamos a deducir que, del texto de Sotelo, se puede sacar fundamentalmente la lectura de la moral. Ya que en la sociedad en la que se inserta la novela analizada, «es innegable que subsiste una conexión entre crisis del humanismo y muerte de Dios» (Vattimo, 1987: 33). Señalemos de entrada que Gilles Lipovetsky (2000: 71) presenta el panorama social de Occidente en la década de los años 80 del pasado siglo con énfasis en las reivindicaciones feministas de cara a poner fin a las derivas sexuales:

Después del imperialismo sexualista de las décadas de 1960 y 1970, nuestras sociedades, cansadas de la orgasmolatría y preocupadas por los virus estarían a punto para la rehabilitación del «amor a distancia» y la disciplina de los sentidos. No ya el goce sino la templanza, no ya las aventuras repetidas sino la higiene de vida, no ya la revolución sexual sino la «sexualidad apacible», no ya las compatibilidades libidinales sino la ternura y las idealizaciones amorosas.

En efecto, Lipovetsky cree que de la decadencia moral de la sociedad cristiana se puede llegar a esta sarta de reivindicaciones de corte ético. Con el mismo autor, «las grandes proclamas moralistas se borran, la ética resurge, la religión de la obligación se vacía más que nunca de su esencia, el "suplemento de alma" está a la orden del día: "El siglo XXI será ético o no será"» (Lipovetsky, 2000: 208). Si la ficción se nutre de la realidad, también huelga señalar que contribuye a transformarla. A través del número tres, con el que está obsesionado el protagonista de la obra analizada, símbolo muy en relación con la imagen de Dios, Justo Sotelo estará abogando por una vida sexual más responsable del hombre posmoderno. La desordenada vida del protagonista es un trampolín para acceder a este ideal. La muerte lenta, título de la obra y polo opuesto de lo que sería «la vida rápida», entonces relacionable con el carácter donjuanesco e insaciable del protagonista, presto a ir de flor en flor, lo que no deja de tener consecuencias para la sociedad.

El carácter donjuanesco del protagonista se debe a que, sentimentalmente, es un personaje frívolo y un cazador ávido. Seduce y enamora a un número importante de mujeres, adolescentes y maduras. Una vez que se haya acostado con una, ella deja de interesarle, por lo que él la abandona para mirar a otra parte. En La muerte lenta, por ejemplo, en pocos años, el joven banquero logra salir sucesivamente con Soledad Jiménez, Rosa María, Marisol Antúnez, Carmina y Leonor, la favorita, con quien se casa por intereses y de quien se divorcia 
luego, después de alcanzar su objetivo: la ascensión profesional. Este rasgo es arquetípico de los protagonistas de Sotelo?.

A partir del elevado grado de ocurrencias del número tres, en La muerte lenta, símbolo de la perfección en la Biblia, se puede captar las preocupaciones de Justo Sotelo en una sociedad en que, aparentemente, van desapareciendo los valores tradicionales de la moral cristiana de la esfera pública ${ }^{8}$. Desde este prisma, se lee en filigrana cierta denuncia al amor desordenado, propio de los protagonistas de nuestro autor, y un ideal a la vuelta a los valores cristianos y al pasado, propia de la postmodernidad, a imagen de su protagonista obsesionado por su propia juventud. El hecho de que haya quedado desconocido el nombre del narrador protagonista puede significar que podría ser el comportamiento de cada uno de los individuos de la sociedad textual descrita, lo que critica Justo Sotelo, ya que en palabras de Bourdieu (1994: 67), «comprendre l'oeuvre, c'est comprendre la vision du monde du groupe social qui se serait trouvée exprimée à travers l'artiste agissant comme une sorte de médium».

\section{CONCLUSIONES}

En suma, a la luz de la temática desarrollada, se puede leer que Sotelo está preocupado por la existencia de un mundo espiritual sin fronteras, al ejemplo de Dios que es universal. Teniendo en cuenta el que no se percibe Dios de modo claro en la novela, reflejo de la vida en que aún Dios no suele estar visible a pesar de su omnipresencia, hemos recurrido a dos operaciones fundamentales para llegar, al fin y al cabo, a vislumbrar su presencia: el

\footnotetext{
${ }^{7}$ Aparte de su interés por lo intelectual, si hay otra cosa característica de todos los protagonistas de Sotelo, es sin duda su comportamiento donjuanesco. Están obsesionados por acostarse con el mayor número posible de mujeres, de todas las edades. En Vivir es ver pasar, César Figueroa sale con Paula Molina, Mara Márquez, María José y Melia Acedarach; en La paz, de febrero, Luis Seoane enamora a Beatriz Cobos, Josefina Arbisu, Isabel Faggiani, Lola Mauricio, María Pineda y Natividad Duarte; en Entrevías mon amour, Teo Abad tiene por amantes a Tamara, la Niña, Marie-France Vivien, Edipa y Judith; y, en fin, en Las mentiras inexactas, Sergio Barrios tiene por víctimas a María José, Magda, Natalie y Nora Acosta.

${ }^{8}$ Lipovetsky presenta el sitio cada vez menos importante que ha ido ocupando Dios a lo largo de los siglos. Según él, en la Europa cristiana, la moral al principio era Dios. Luego ha ido reforzándose este teocentrismo, hasta el siglo xvii cuando el proceso de secularización puesto en marcha aboga por la separación moral de las concepciones religiosas. Ello se debe a que el principio de la moral ha ido relacionándose con la felicidad del hombre frente a Dios, lo cual implica que la moral se haya convertido en un derecho y no en un deber. La ética llega entonces a convertirse en un orden de valores superior a la religión. Pero en las sociedades postmorales, hay un cambio de paradigma de los valores que llegan a su crepúsculo. Como dice Lipovetsky (2000: 49), «hemos pasado a una civilización del deber a una cultura de la felicidad subjetiva, de los placeres y del sexo: la cultura del self-love nos gobierna en lugar del antiguo sistema de represión y de control dirigista de las costumbres».
} 
título de la novela analizada que sugiere la manera cómo ha muerto Cristo, metáfora de Dios quien, por su parte, puede captarse desde las fuertes ocurrencias de la cifra tres, a imagen de la Trinidad. El narrador protagonista de la obra utiliza un grado elevado de la cifra tres en sus conversaciones diarias y desde nuestro punto de vista, esto ha merecido interpretarse, para captar uno de los sentidos de la obra en cuestión.

Varios son entonces los resultados a los que hemos llegado. En primer lugar, por las fluctuaciones entre presencia ausente o ausencia presente de Dios, como se ha observado, La muerte lenta representa a la vez el símbolo de la ausencia del Dios de la Ilustración y el fracaso de la modernidad, así como un ideal de la vuelta a los valores morales premodernos. De esta manera, Sotelo plasma los hechos de manera fría, mira la realidad presente desde cierta distancia y la critica mediante cierta ironía. Recurre al pasado, a través de sus personajes propensos a la nostalgia y muy volcados hacia los recuerdos de su infancia. Por lo que la obra aboga indirectamente por la vuelta a la moral cristiana. Esto se lee a través del comportamiento donjuanesco del protagonista presentado por Justo Sotelo para que cualquier lector pueda percibir la urgencia de una educación sentimental. En segundo lugar, La muerte lenta es una novela universalista, si nos atenemos a la temática tratada, Dios. El Dios de Sotelo es el Dios de la posmodernidad. Es líquido, evanescente y etéreo. Está vertido en La muerte lenta, lo que justifica el que no se le perciba a primera lectura. A través de su presencia, aunque escasa y transparente, se puede leer cierto deseo de Sotelo de que los seres humanos vuelvan a reconsiderar y a revalorar su relación con Dios y con su pasado, a ejemplo del protagonista de la novela analizada. 


\section{BIBLIOGRAFÍA}

Barthes, Roland (1993): La aventura semiológica, traducción al español de Ramón Alcalde, Barcelona, Paidós [1985].

Bauman, Zygmunt (2003): Modernidad líquida, traducción al español de Mirta Rosenberg, Buenos Aires, Fondo de Cultura Económica de Argentina [2000].

Bourdieu, Pierre (1994): Raisons pratiques. Sur la théorie de l'action, Paris, Seuil.

Butor, Michel (1957). La modification, Paris, Editions de Minuit.

Conferencia Episcopal Española (2012): Sagrada Biblia, Madrid, Biblioteca de Autores Cristianos.

De la Fuente González, Miguel Ángel (1997-1998): «Funciones de los títulos en la descodificación lectora», en Tabanque, 12-13: 185-201.

Desrosiers, Steve (2005): Les nombres: symbolisme et propriétés, Québec, Editions Protestantes.

Eagleton, Terry (2014). Culture and the Death of God, New Haven, University Press.

Eagleton, Terry (2017): Cómo leer literatura, Traducción de Albert Vitó, Barcelona, Austral [2013].

Eco, Umberto (1992): Los límites de la interpretación, traducción al español de Helena Lozano, Barcelona, Lumen [1990].

Ezquerro, Milagros (1998): «Fragments sur le texte», en Edmond Cros (dir.), Questionnements des formes, questionnements du sens, Tome I, Montpellier, CERS: 87-99.

Frye, Northrop (1982). The Great Code: The Bible and Literature, New York, Harcourt Brace Jovanovich.

Gutiérrez Carbajo, Francisco (2013): Movimientos y épocas literarias, Madrid, Cuadernos de la Universidad Nacional de Educación a Distancia.

Kristeva, Julia (1978). Semiótica 1, traducción al español de José Martín Arancibia, Madrid, Fundamentos [1969].

Kristeva, Julia (1986): Al comienzo era el amor. Psicoanálisis y fe, traducción al español de Graciela Klein, Buenos Aires, Gedisa [1985].

Lipovetsky, Gilles $\left(2000^{5}\right)$ : El crepúsculo del deber. La ética indolora en los nuevos tiempos democráticos, traducción al español de Juana Bignozzi, Barcelona, Anagrama [1992].

Lozano Mijares, María del Pilar (2007): La novela española postmoderna, Madrid, Arco/Libros.

Mbarga, Jean-Claude (1991): «Mosén Millán o Réquiem por un campesino español, de Ramón José Sender. Notas sobre un dilema "titulógico"», en Lenguaje y Textos, 8: 341-343. 
Murugarren, José Díaz (1989): «Postmodernidad y cristianismo», en Ciencia Tomista, 116: 129148.

Pérez B., Claudio H. (2012): «Dios en el pensamiento posmoderno: hacia una teología de la muerte o de la afirmación de la vida», en Revista Espiga, XI, 23: 127-144.

Rubio Fernández, Juan (2013): «Las huellas de Dios en la literatura contemporánea», en https://www.dominicos.org/noticia/las-huellas-de-dios-en-la-literaturacontemporanea/ (Último acceso: 15/08/2019).

Sábato, Ernesto (2014): El escritory sus fantasmas, Barcelona, Seix Barral.

Sotelo, Justo (1995): La muerte lenta, Madrid, Ediciones Libertarias.

Sotelo, Justo (1997): Vivir es verpasar, Madrid, Editorial Huerga y Fierro.

Sotelo, Justo (2002): La paz de febrero, Editorial Huerga y Fierro.

Sotelo, Justo (2009): Entrevías mon amour, Madrid, Narrativa Bartleby.

Sotelo, Justo (2012): Las mentiras inexactas, Madrid, Izana Editores.

Sotelo, Justo (2017): Cuentos de los otros, Madrid, Narrativa Bartleby.

Todorov, Tzvetan $\left(1974^{2}\right)$ : Literatura y significación, traducción al español de Gonzalo Suárez Gómez, Caracas, Monte Ávila Editores [1967].

Todorov, Tzvetan $\left(1993^{3}\right)$ : Teorías del simbolo, traducción al español de Francisco Rivera, Caracas, Monte Ávila Editores [1977].

Vattimo, Gianni $\left(1987^{2}\right)$ : El fin de la modernidad. Nibilismo y hermenéutica en la cultura posmoderna, traducción al español de Alberto L. Bixio, Barcelona, Gedisa [1985].

Vattimo, Gianni (2004): Nibilismo y emancipación: ética, politica, derecho, traducción al español de Carmen Revilla, Barcelona, Paidós [2003]. 


\section{Patrick Toumba Haman}

Patrick Toumba Haman es Doctor Cum Laude (2014) en literatura española contemporánea por la Universidad Complutense de Madrid, donde cursó un Máster de la misma especialidad (2012). Por otra parte, es titular de un Máster en Diplomacia y Relaciones Internacionales (2014), obtenido en la Escuela Diplomática de España. Profesor de español como Lengua Extranjera, ha trabajado, entre 2005 y 2011, en el área de la pedagogía en el ministerio de la enseñanza secundaria de su país. Entre 2010 y 2011 ha sido representante, en Camerún, del Centro de Estudios Internacionales de Biología y Antropología (CEIBA), y en 2016, en ocasión al cuarto centenario de la muerte de Miguel de Cervantes, ha colaborado en el extraordinario proyecto 'El Quijote Universal', publicado por Antonio Machado Editores, con la traducción a su lengua materna, el guidar, del capítulo 47 de la Primera Parte. En la actualidad, es profesor titular de literatura española en la Universidad de Maroua, en Camerún y autor de varios artículos sobre literatura española, literatura comparada y antropología.

Contact information: email: toumbahamanpat@yahoo.fr 